Research Article

\title{
A Report on Vector Surveillance for Zika/Dengue at CCS International Airport, Lucknow, India
}

\author{
Shaukat Kamal, Ramesh Chandra, SM Singh, Ashish Kumar, Rahul Kumar Singh, \\ VKChaudhary, KK Mittra
}

Regional Office of Health \& Family Welfare, Government of India, Kendriya Bhawan, 9th Floor, Aliganj, Lucknow, India. DOI: https://doi.org/10.24321/0019.5138.202141

\section{I $\quad \mathbf{N} \quad \mathbf{F} \quad \mathbf{O}$}

\author{
Corresponding Author: \\ Shaukat Kamal, Regional Office of Health \& Family \\ Welfare, Government of India, Kendriya Bhawan, \\ 9th Floor, Aliganj, Lucknow, India. \\ E-mail Id: \\ shaukatkamal25@yahoo.in \\ Orcid Id: \\ https://orcid.org/0000-0002-3358-1572 \\ How to cite this article: \\ Kamal S, Chandra R, Singh SM, Kumar A, Singh \\ RK, Chaudhary VK, Mittra KK. A Report on \\ Vector Surveillance for Zika/Dengue at CCS \\ International Airport, Lucknow, India. J Commun \\ Dis. 2021;53(3):76-79.
}

Date of Submission: 2021-06-05

Date of Acceptance: 2021-08-07

\section{$\begin{array}{llllllll}\mathbf{A} & \mathbf{B} & \mathbf{S} & \mathbf{T} & \mathbf{R} & \mathbf{A} & \mathbf{C} & \mathbf{T}\end{array}$}

In view of reports of Zika outbreak from Gujarat \& Rajasthan states, an entomological surveillance of Aedes aegypti vector was carried out at Adani Chaudhary Charan Singh (CCS) International Airport, Lucknow and its adjoining areas between 2016 to 2019. The regular monitoring of the vector and effective intervention measures prevented the invasion of new pathogen of Zika and Yellow fever pathogen (virus) by bringing down the Aedes aegypti vector density at lowest level. The entomological indices worked out in 2016 as the premise index in the month of February, June and August, were remained positive for Aedes aegypti and container index (CI) was found 14.14. The House Index (HI), Container Index (Cl) \& Breteau Index (BI) were 24.50, 17.51 $\& 25.27$, respectively in residential colony of Air Port Staff located at a distance of $0.50 \mathrm{~km}$, whereas, indices were found very high i.e. 37.50, 25.50 \& 57.62, respectively in Farrukhabad/Chillawan civil inhabitation located at a distance of 2.0 Kilometre. With the dedicated efforts of Airport Authority of India and State Health Department, Aedes aegypti indices gradually declined to very low level as the premise were positive for Aedes aegypti larvae but container index inside \& outside airport premise became $2.70 \& 4.37$ respectively in early half of 2019 . The $\mathrm{HI}$, $\mathrm{Cl} \& \mathrm{BI}$ were found $2.57,2.69 \& 3.09$ in the airport residential colony and $3.15,2.57 \& 2.77$, respectively in civil inhabitation i.e. Farrukhabad/ Chillawan area in early half of 2019. The collateral impact of low vector density resulted drastic decline in dengue morbidity by $83.73 \% \& 74.74 \%$ and in mortality by $88.89 \% \& 94.44 \%$, during $2017 \& 2018$ respectively in comparison to 2016 and the case fatality rate (CFR) declined from $0.65 \%$ in 2016 to $0.14 \%$ in 2018 . However no death was documented due to Chikungunya in Lucknow and the morbidity though was doubled in 2017 \& declined again to the level of 2016, but remained very less in comparison to dengue, as only $44,80 \& 47$ cases of Chikungunya were reported during 2016, $2017 \& 2018$, respectively. The Airport also achieved the dividend in the form of conferring the title of Best Airport of the year 2018 in size \& region managing the cleanliness in increased thrust of passengers' load to more than double in limited resources.

Keywords: Arbo Viruses, Zika Outbreak, Dengue, Chikunguniya, Surveillance, Aedes aegypti, Intervention Measures, Source Reduction

Journal of Communicable Diseases (P-ISSN: 0019-5138 \& E-ISSN: 2581-351X) 


\section{Introduction}

The arbo viral diseases like Dengue, Chikunguniya, and Yellow Fever \& Zika are transmitted among human beings by tiger mosquito, Aedes aegypti both in urban and rural settings. Uttar Pradesh has experienced outbreaks of Dengue \& Chikungunya from the end of the 20th century. Although Yellow fever \& Zika have not been reported from the state, but there are risks of these diseases as some cases of Zika were reported from Gujarat \& Rajasthan states in the middle of 2 nd decade of the 21st century. Due to the habits of mosquito, it is a potent vector of not only dengue \& Chikunguniya but also posing threat of Zika \& Yellow fever in India. The vector is widely spread in tropical region including Indian subcontinent and gradually established itself in all the 75 districts of the state by the end of the second decade. Aedes aegypti and Aedes albopictus presence in all the districts of the state has put in alarming situation for spread of any new arbo viral diseases, though the dengue was considered as emerging disease $\mathrm{e}^{1}$ in near past and resulted outbreak too in 1993 in U.P. ${ }^{2}$ but introduction of Zika has drawn the attention of the higher authorities. Though the International Health Regulations (IHR), 1969 laid emphasis to national government to keep International Airports \& Seaports free from Aedes aegypti mosquito, both adult and larval stages up to about half $(0.40)$ kilometre distance from ports. The junkyards of ports and nearby inhabitations provide congenial conditions for development of Aedes aegypti mosquito. The distance from the port for undertaking entomological surveillance and control may be extended over 03.00 kilometres depending up on the flight range of Aedes aegypti. ${ }^{11}$ The role of entomological surveillance is most important in preventing and instituting the intervention measures to contain the outbreaks of these arboviruses. ${ }^{3}$

Uttar Pradesh experienced large scale outbreaks of dengue in 2016 and reported 15033 dengue cases with 42 deaths, of which 2772 cases \& 18 deaths were contributed by Lucknow district alone. Thus the pronounced vector presence was experienced in Lucknow during 2016. Due to reports of Zika from Gujarat \& Rajasthan states in India, Ministry of Health \& Family Welfare (MOH \& FW), Government of India issued advisory for keeping close vigil on the of invasion of new arbo viral diseases from possible introduction sites like Airports \& seaports, ${ }^{10}$ where from there are movement of either arboviral infected human or mosquito population, which can infect the vector population present in and around such international sites. The entomological surveillance for Aedes aegypti has been carried out in cities of industrial significance $e^{4-5}$ and airports and seaports for dengue \& chikungunya. ${ }^{6-9}$ Since, there has been no report of Zika or Yellow Fever from the state, the only entry point of the pathogen (virus) could be the International Airport as there is no seaport. Therefore, entomological surveillance of Aedes aegypti mosquito was carried out from 2016 to 2019 in and around CCS International Airport, Lucknow.

The airport was granted International status in May 2012, when only few international flights operated to middle east Asian countries and the passenger load remained about 2 million per annum. However, the number of flight operation in domestic and international terminals doubled by the year 2016. Currently, 140 flights (including 8 International flights) are in operation per day from Lucknow airport, there by increasing total passenger load to 5.7 million passengers per annum by the year 2018. Keeping in view the gravity of the prevailing situation, regular entomological surveillance was conducted to assess the Aedes aegypti prevalence in the Airport area and prevent any unprecedented outbreak of disease like Zika, Yellow fever, which may invade through the air route. Thus, the study was undertaken with the objective to: (i) Educate the airport authorities and officials responsible for flight operation, regarding identification \& elimination of mosquito breeding habitats within and outsides the airport premises, (ii) Ensure mosquito/vector free airport both adult and larval stages up to about half kilometre and even 2.0 to $5.0 \mathrm{~km}$ distance from the airport, and (iii Ensure implementation of anti-mosquito/vector operations by Municipal corporation/health authorities in the civil inhabitations located within a distance of 0.2 kilometres from the airport.

The impact of such coordinated action of airport and state health authorities will not only prevent the spread of Zika \& Yellow fever but also the Dengue \& Chikungunya in the airport area, which operates 132 domestic $\& 08$ International flights per day. Moreover, the airport may attain clean, healthy and mosquito free environment.

\section{Methodology}

Chaudhary Charan Singh (CCS) International Airport (Now Adani Lucknow International Airport Limited), Lucknow is located at $26.8467^{\circ} \mathrm{N}, 80.9462^{\circ} \mathrm{E}$ and experiences extreme climatic conditions. The survey of Aedes mosquito and its breeding places was conducted in and around Chaudhary Charan Singh International Airport, Lucknow settings as well as among inhabitations up to $2.0 \mathrm{kms}$ perimeter from 2016 to 2019. The mosquito larvae were collected from different types of containers holding fresh water and were reared in cages measuring $30 \times 30 \mathrm{~cm}$ by putting them in beakers $250 \mathrm{ml}$ capacity at room temperature $25 \pm 5^{\circ} \mathrm{C}$ and $65 \pm 5 \%$ relative humidity $(\mathrm{RH})$. The adults emerged from larvae/ pupae were identified. The data collected so for breeding places of the Aedes, was analyzed and various indices like House Index ( $\mathrm{HI}$ ), Container Index ( $\mathrm{Cl}$ ) and Breteau Index (BI) were calculated. However, the domestic and international terminals were considered as two separate premises for the purpose of calculating the indices. Officials of airport 
authority of India (AAI) and the agency involved in hygiene, sanitation and pest/vector management were oriented for identification and elimination of breeding places of Aedes aegypti mosquito in \& outside of airport premises so that not only airport premises but neighbouring inhabitations may be kept free from any mosquito. The state health department was involved to keep close vigil in the civil inhabitation falling at a distance of 2.0 kilometres.

The findings of entomological surveillance for Aedes aegypti conducted from 2016 to 2019 in and around Chaudhary Charan Singh International Airport, Lucknow and among inhabitations up to $2.0 \mathrm{kms}$ perimeter are presented in this document. The data obtained so was statistically analyzed.

\section{Results and Discussion}

The findings of entomological surveillance for Aedes aegypti conducted for four years from 2016 to 2019 in and around CCS International Airport, Lucknow and among inhabitations up to 2.0 kilometres perimeter are presented in Table 1.

It is evident from the Table 1, that the entomological indices worked out in 2016 as the premise index in the month of February, June and August, were remained positive for Aedes aegyptiand container index $(\mathrm{Cl})$ was found 14.14 . The House Index ( $\mathrm{HI})$, Container Index (Cl) \& Breteau Index (BI) were $24.50,17.51 \& 25.27$, respectively in residential colony of Air Port Staff located at a distance of $0.50 \mathrm{~km}$, whereas, indices were found very high i.e. 37.50, $25.50 \& 57.62$, respectively in Farrukhabad/Chillawan civil inhabitation located at a distance of 2.0 kilometres.

The higher officials of Airport Authority of India and State Health authorities were timely informed to take intervention measures in order to check the breeding, because the adults emerged from the larvae \& pupae, confirmed the presence of Aedes aegypti. Airport Authority of India and State Health authorities conducted intensified drives regularly to eliminate mosquito breeding and maintained the cleanliness inside as well as outside the airport premises together with the residential colony of the airport staff. The State Health authorities restricted drives up to the civil inhabitations i.e. Farrukhabad/ Chillawan area near airport, as a result of which the indices of Aedes aegypti gradually declined to very low level as the premise were though positive for Aedes aegypti larvae but container index inside \& outside airport premise became $2.65 \& 4.37$ respectively in early half of 2019. The $\mathrm{HI}, \mathrm{Cl} \& \mathrm{BI}$ were found 2.57, $2.69 \& 3.09$ in the airport residential colony and 3.13, $2.57 \& 2.77$, respectively in civil inhabitation i.e. Farrukhabad/Chillawan area in early half of 2019. The efforts of Airport Authority of India and State Health authorities could succeed in keeping the density of Aedes aegypti at the lowest, due to which no case of Zika or Yellow fever was reported from Lucknow and could prevent the invasion of the disease from abroad. The collateral impact was experienced on spread of dengue and Chikunguniya (Table 2) as drastic decline in dengue morbidity by $83.73 \% \& 74.74 \%$ and in mortality by $88.89 \%$ \& 94.44\%, during 2017 \& 2018, respectively, after a severe outbreak of dengue during 2016 (Table 2). Moreover, the case fatality rate (CFR) declined from $0.65 \%$ in 2016 to $0.14 \%$ in 2018 . However no death was documented due to Chikungunya in Lucknow and the morbidity though was doubled in 2017 \& declined again to the level of 2016, but remained very less in comparison to dengue, as only 44,80 $\& 47$ cases of Chikungunya were reported during 2016, 2017 \& 2018, respectively. This achievement can be attributed more to the activities performed by the active participation of the Airport Authority of India and State Health authorities $\&$ community in reducing the breeding sources.

Table I.Entomological Indices for Aedes aegypti in and around CCS International Airport, Lucknow from 2016 to 2019

\begin{tabular}{|c|c|c|c|c|c|c|}
\hline S. No. & Locality Surveyed & Entomological Indices & 2016 & 2017 & 2018 & 2019 \\
\hline \multirow{3}{*}{1.} & \multirow{3}{*}{$\begin{array}{c}\text { Inside Terminal - I \& } \\
\text { II (International \& } \\
\text { Domestic) }\end{array}$} & HI (Premises) & +ive & +ive & +ive & +ive \\
\hline & & $\mathrm{Cl}$ & 14.14 & 07.05 & 01.92 & 02.65 \\
\hline & & $\mathrm{BI}$ & - & - & - & - \\
\hline \multirow{3}{*}{2.} & \multirow{3}{*}{$\begin{array}{l}\text { Outside Terminal - I } \\
\text { \& II (International \& } \\
\text { Domestic) }\end{array}$} & HI (Premises) & +ive & +ive & +ive & +ive \\
\hline & & $\mathrm{Cl}$ & 15.42 & 15.67 & 02.00 & 04.37 \\
\hline & & $\mathrm{BI}$ & - & - & - & - \\
\hline \multirow{3}{*}{3.} & \multirow{3}{*}{$\begin{array}{c}\text { Airport Staff Residential } \\
\text { Colony }\end{array}$} & $\mathrm{HI}$ & 24.50 & 03.01 & 01.88 & 02.57 \\
\hline & & $\mathrm{Cl}$ & 17.51 & 01.37 & 01.74 & 02.69 \\
\hline & & $\mathrm{BI}$ & 25.27 & 03.01 & 01.88 & 03.09 \\
\hline \multirow{3}{*}{4.} & \multirow{3}{*}{$\begin{array}{c}\text { Farrukhabad/Chillawan } \\
\text { Civil Inhabitation in } \\
\text { Front of Airport }\end{array}$} & $\mathrm{HI}$ & 37.50 & 07.93 & 03.72 & 03.13 \\
\hline & & $\mathrm{Cl}$ & 25.50 & 07.46 & 03.38 & 02.57 \\
\hline & & $\mathrm{BI}$ & 57.62 & 10.00 & 03.72 & 02.77 \\
\hline
\end{tabular}

$\mathrm{HI}=$ House Index (Airport Premise considered as a whole one unit); $\mathrm{Cl}=$ Container Index; $\mathrm{BI}=\mathrm{Breteau}$ Index. 
Table 2.Year wise Dengue \& Chikungunya Cases \& Deaths in Lucknow (Uttar Pradesh)

\begin{tabular}{|c|c|c|c|c|c|c|}
\hline S. No. & Year & Dengue cases & $\begin{array}{c}\text { Deaths due to } \\
\text { dengue }\end{array}$ & CFR (\%) & $\begin{array}{c}\text { Chikungunya } \\
\text { cases }\end{array}$ & $\begin{array}{c}\text { Deaths due to } \\
\text { chikungunya }\end{array}$ \\
\hline 1. & 2016 & 2772 & 18 & 0.65 & 44 & 00 \\
\hline 2. & 2017 & 451 & 02 & 0.44 & 80 & 00 \\
\hline 3. & 2018 & 700 & 01 & 0.14 & 47 & 00 \\
\hline
\end{tabular}

The dedicated efforts of authorities of Chaudhary Charan Singh (CCS) International Airport, Lucknow, not only prevented the invasion of the new pathogen of Zika \& Yellow fever but enabled the airport to get the best Airport title of 2018.

\section{Conclusion}

On the basis of results \& discussion, it can be concluded that the regular and timely monitoring of Aedes aegypti vector at appropriate entry points and effective intervention measures may prevent the invasion of new pathogen, for which it is known vector in other countries and may decline the spread of already circulating pathogens in the indigenous environment as has been observed in the present findings. The invasion of Zika and Yellow fever pathogen (virus) could be prevented in Lucknow by bringing down the Aedes aegypti vector density at lowest level. The collateral impact of low vector density resulted a drastic decline in dengue morbidity by $83.73 \% \& 74.74 \%$ and in mortality by $88.89 \% \& 94.44 \%$, during $2017 \& 2018$, respectively in comparison to 2016 and the case fatality rate (CFR) also declined from 0.65\% in 2016 to $0.14 \%$ in 2018 . However no death was documented due to Chikungunya in Lucknow and the morbidity though was doubled in 2017 \& declined again to the level of 2016, but remained very less in comparison to dengue, as only 44 , $80 \& 47$ cases of Chikungunya were reported during 2016, 2017 \& 2018, respectively. The Airport also achieved the dividend, as it was conferred with the title of Best Airport of the country during 2018 in size \& region managing the cleanliness in increased thrust of passengers' load to more than double within limited resources.

\section{Acknowledgements}

The authors are thankful to Air Port Authority of India Officers especially Mr. V. K. Lohat, DGM (Operations), CCS International Airport, Lucknow and Dr. D. N. Shukla, District Malaria/VBD Officer, Lucknow for their valuable inputs and support rendered for completing the present survey. Thanks are also due to Dr. Anil Kumar, ex-Scientist F, ICMR, Govt. of India, for their useful suggestions \& necessary inputs.

\section{Conflict of Interest: None}

\section{References}

1. Sharma SN, Raina VK, Kumar A. Dengue/DHF: An emerging disease in India. J Commun Dis. 2000 Sep;32(3):175-9. [PubMed] [Google Scholar]
2. Jamal Uddin $M$, Jalees $S$, Sharma RS, Verghese T. Dengue fever/dengue haemorrhagic fever outbreak in Shahjahanpur, Uttar Pradesh. Dengue News Letter. 1993;18:2. [Google Scholar]

3. Kaul SM, Sharma RS, Sharma SN, Panigrahi N, Phukan PK, Lal S. Preventing dengue /dengue haemorrhagic fever outbreak in National Capital Territory of Delhi-The role of entomological surveillance. J Commun Dis. 1998 Sep;30(3):187-92. [PubMed] [Google Scholar]

4. Sharma SK, Pradhan K, Rath Y, Subba Rao SK. Observations on breeding habit of Aedes species in the Steel Township, Rourkela. J Commun Dis. 2001 Mar;33(1):28-35. [PubMed] [Google Scholar]

5. Ravi Kumar R, Kamal S, Patnaik SK, Sharma RC. Breeding habitats and larval indices of Aedes aegypti $(\mathrm{L})$ in residential areas of Rajahmundry town, Andhra Pradesh. J Commun Dis. 2002 Mar;34(1):50-8. [PubMed] [Google Scholar]

6. Kamal S, Patnaik SK, Sharma SK, Rao JS. A Study on the breeding habitats of Aedes species around Visakhapatnam Sea Port. J Commun Dis. 2003 Mar;35(1):52-5. [PubMed] [Google Scholar]

7. Das BP, Sharma SK, Dutta KK. Prevalence of Aedes aegypti at the International Port Airport, Kolkata (West Bengal), India. Dengue Bulletin. 2000;24:124-6. [Google Scholar]

8. Das BP, Kabilan L, Sharma SN, Lal S, Regu K, Saxena VK. Detection of dengue virus in wild caught Aedes albopictus (Skuse) around Kozhikode Airport, Malappuram district, Kerala, India. Dengue Bulletin. 2004;28:210-2. [Google Scholar]

9. Sharma SN, Kumar S, Das BP, Thomas TG, Kumar K, Katyal R, Gill KS, Bora D, Lal S, Saxena VK. Entomological indices of Aedes aegypti at some International airports and seaports of Southern India-a report. J Commun Dis. 2005 Sep;37(3):173-81. [Google Scholar]

10. Kumar K, Sharma A, Sarkar M, Chauhan A, Sharma R. Surveillance of Aedes aegypti (L) mosquitoes in Mumbai International Seaport (India) to monitor potential global health risks. Journal of Insects. 2014, p.1-5. [Google Scholar]

11. Kollars TM Jr. Identifying likely invasion sites of Zika virus infected mosquitoes through air and sea ports in Mumbai, India. J. Med. Dental Sci. Res. 2017;3(12):268. [Google Scholar] 